\title{
AOR
}

Selected Papers of \#AolR2020: The $21^{\text {st }}$ Annual Conference of the Association of Internet Researchers Virtual Event / 27-31 October 2020

\section{PLATFORM LOGIC AND THE INFRASTRUCTURAL POWER OF TECH GIANTS}

Jean-Christophe Plantin

London School of Economics and Political Science

While Alphabet, Facebook, and Microsoft are mostly associated with online services and mobile applications, they now constitute important actors of global communication networks. This paper investigates this infrastructural expansion of tech giants in four sectors: data centers, subsea cables, telecommunication networks, and non-terrestrial connectivity. Its central hypothesis is that tech giants become a dominant force shaping the global infrastructure by leveraging in the connectivity sector the platform logic that granted them their initial success in the web economy (Gillespie, 2010; Helmond, 2015; Srnicek, 2016; José van Dijck et al., 2018).

The infrastructural growth of tech giants takes two forms. The first and most visible consists of direct investments in infrastructure projects. For example, Google has invested $\$ 30$ billion since 2015 in its data centres and undersea cables, and currently owns part or all of eleven subsea cables ( $8.5 \%$ of undersea cables worldwide). Since 2013, Facebook has been teaming up with local service providers to provide low-cost mobile access through the project Internet.org. Google Fiber provides fiber-to-the-home in various U.S. cities (albeit with various levels of success). The Alphabet-founded Loon project is currently tested in Peru to deploy internet access through balloons after environmental crisis. Amazon opened in 2019 a global network of ground stations for access and management of satellites capacities.

While these spectacular (and sometimes failed) infrastructure projects have gained wide media coverage, a second look at these transformations reveal how internet companies are not only building infrastructures, but also changing the ways they are managed. They do so by adapting the platform model from the web economy to communication networks. Literature in management and platform studies have highlighted key characteristics of this platform logic, e.g. a new intermediary creating two-sided or multisided markets (Rochet \& Tirole, 2003), relying on datafication to generate network effects (van Dijck, 2014), or making content programmable (Helmond, 2015). Tech giants now adapt this platform logic to enter and to reorganize infrastructural markets, hereby allowing them to bypass incumbent companies and to eventually position themselves as central actors operating communication networks.

Suggested Citation (APA): Plantin, JC. (2020, October) Platform Logic and the Infrastructural Power of Tech Giants. Paper presented at AolR 2020: The 21 ${ }^{\text {th }}$ Annual Conference of the Association of Internet Researchers. Virtual Event: AolR. Retrieved from http://spir.aoir.org. 
An illustrative example at the core of this paper is the Open Compute Project, a consortium in the data center industry that Facebook impulsed in 2011. Its objective is to promote open source hardware for data centers by inviting its members to share design specs. The long-term goal is to break free from the dependence towards blackboxed components sold by legacy manufacturers (such as IBM or Cisco) and to replace them by modular and programmable components. To do so, the consortium leverages the platform model: it reorganizes a vertical market into a two-sided market connecting manufacturers and buyers of data center components, that the consortium can mediate and supervise. Similar to an app store, this platform allows Facebook and its partners to act as gatekeepers: they can channel innovation efforts in one direction over another, and select the types of products that will be sold on the consortium marketplace.

In addition to data centers, tech giants deploy a similar strategy with undersea cables, telecommunications, and satellites. The comparison between these four sectors is based on interviews with industry experts and network engineers, document analysis, and site visits, and it reveals a model of platformization of communication networks that comprises the four following stages:

1. Disaggregating black-boxed technologies

The platform strategy is first used to break up closed technologies into smaller components that can each be developed, managed, or upgraded separately. For example, in the subsea cable industry, the "open cable" model promoted by Microsoft or Alphabet disaggregates the "dry plant" (comprising the cable landing stations and routers) from the "wet plant" (the actual cables and signal repeaters), instead of having both built and managed by the same company.

2. Inserting of a platform

Once network components are disaggregated, a platform is inserted to integrate them all together. In the telecom sector, the various platforms developed by the Open Networking Foundation link together the disaggregated components of a telecommunication network (cell tower, backhaul, data centers, etc).

3. Making components modular With network components now modular, they can each be changed or updated separately. The Open Compute Project mentioned earlier promotes a model of data center maintenance presented as "tool free" and allowing "hot swap:" a piece of hardware can be removed and replaced simply by pressing a lever and without having to switch off the whole rack (i.e. while being still "hot").

4. Making networks programmable As platforms are based on APIs, network operators can extract data about the state of the networks and program new features on the spot. "Programmable satellite" is such data-driven paradigm allowing the change of orientation of a satellite or of the types of data it extracts after its launch.

Disaggregating networks, inserting a platform, making networks modular and programmable: this is the model that tech giants are currently using to take control over 
the global infrastructure for connectivity. By detailing this model, this paper makes two contributions. First, it complements the critical analysis of tech giants' infrastructural growth (Author et al, 2018) by going beyond the current focus on their cloud computing capacities (Hogan, 2015; Mosco, 2014) or their most publicized failed projects (Halegoua, 2015; Prasad, 2018). Second, while studies on the social implications of tech giants focuses on their technical architecture, ecosystems of apps, and data circulation (Gillespie, 2018; Helberger et al., 2017; Mansell, 2015; van Dijck et al., 2018), this paper provides a comprehensive study of the multifaceted infrastructural expansion of tech giants and the power they gain over global connectivity.

Author et al, 2018

Gillespie, T. (2010). The politics of 'platforms'. New Media \& Society, 12(3), 347-364.

Gillespie, T. (2018). Custodians of the Internet: Platforms, Content Moderation, and the Hidden Decisions That Shape Social Media. Yale University Press.

Halegoua, G. (2015). Calling all 'fiberhoods': Google Fiber and the politics of visibility. International Journal of Cultural Studies, 18(3), 311-316.

Helberger, N., Pierson, J., \& Poell, T. (2017). Governing online platforms: From contested to cooperative responsibility. The Information Society, O(0), 1-14.

Helmond, A. (2015). The Platformization of the Web: Making Web Data Platform Ready. Social Media + Society, 1(2). https://doi.org/10.1177/2056305115603080

Hogan, M. (2015). Data flows and water woes: The Utah Data Center. Big Data \& Society, 2(2).

Mansell, R. (2015). The public's interest in intermediaries. Info, 17(6), 8-18.

Mosco, V. (2014). To the Cloud: Big Data in a Turbulent World. Paradigm Publishers.

Prasad, R. (2018). Ascendant India, digital India: How net neutrality advocates defeated Facebook's Free Basics. Media, Culture \& Society, 40(3), 415-431.

Rochet, J.-C., \& Tirole, J. (2003). Platform Competition in Two-Sided Markets. Journal of the European Economic Association, 1, 990-1029.

Srnicek, N. (2016). Platform Capitalism. Polity Press.

van Dijck, José. (2014). Datafication, dataism and dataveillance: Big Data between scientific paradigm and ideology. Surveillance \& Society, 12(2), 197-208.

van Dijck, José, Poell, T., \& Waal, M. de. (2018). The Platform Society. Oxford University Press. 